\title{
Complete nucleotide sequence of pRS218, a large virulence plasmid, that augments pathogenic potential of meningitis-associated Escherichia coli strain RS218
}

Dona Saumya S Wijetunge ${ }^{1}$, Kurundu Hewage Eranda M Karunathilake ${ }^{1}$, Atul Chaudhari ${ }^{1}$, Robab Katani ${ }^{1}$, Edward G Dudley ${ }^{2,3}$, Vivek Kapur ${ }^{1}$, Chitrita DebRoy ${ }^{1}$ and Subhashinie Kariyawasam ${ }^{1,3^{*}}$

\begin{abstract}
Background: Escherichia coli is the most predominant Gram-negative bacterial pathogen associated with neonatal meningitis. Previous studies indicated that the prototypic neonatal meningitis E. coli (NMEC) strain RS218 (O18:K1: $\mathrm{H7}$ ) harbors one large plasmid. Objectives of the present study were to analyze the complete nucleotide sequence of this large plasmid (pRS218) and its contribution to NMEC pathogenesis using in vitro and in vivo models of neonatal meningitis.

Results: The plasmid is 114,231 bp in size, belongs to the incompatibility group FIB/IIA (IncFIB/IIA), and contains a genetic load region that encodes several virulence and fitness traits such as enterotoxicity, iron acquisition and copper tolerance. The nucleotide sequence of pRS218 showed a 41-46\% similarity to other neonatal meningitis-causing E. coli (NMEC) plasmids and remarkable nucleotide sequence similarity (up to 100\%) to large virulence plasmids of $E$. coli associated with acute cystitis. Some genes located on pRS218 were overly represented by NMEC strains compared to fecal E. coli isolated from healthy individuals. The plasmid-cured strain was significantly attenuated relative to the RS218 wild-type strain as determined in vitro by invasion potential to human cerebral microvascular endothelial cells and in vivo by mortalities, histopathological lesions in the brain tissue, and bacterial recovery from the cerebrospinal fluid of infected rat pups.

Conclusions: The pRS218 is an IncFIB/IIA plasmid which shares a remarkable nucleotide sequence similarity to large plasmids of E. coli associated with cystitis. Both in vitro and in vivo experiments indicated that pRS218 plays an important role in NMEC pathogenesis.
\end{abstract}

Keywords: DNA sequence, Escherichia coli, Neonates, Meningitis, Plasmid, Virulence

\section{Background}

Neonatal meningitis (NM) and sepsis is the third most common disease in neonates that accounts for approximately 393,000 deaths per year worldwide [1]. Escherichia coli has been identified as the most predominant Gram-negative pathogen associated with NM [2-5]. Despite advanced antimicrobial therapy and supportive

\footnotetext{
* Correspondence: sxk91@psu.edu

${ }^{1}$ Department of Veterinary and Biomedical Sciences, Pennsylvania State

University, 16802 University Park, PA, USA

${ }^{3}$ Center for Molecular Immunology and Infectious Disease, 16802 University

Park, PA, USA

Full list of author information is available at the end of the article
}

care, mortality and morbidity rates of NM due to neonatal meningitis-associated E. coli (NMEC) continue to be as high as $30-50 \%$ [6]. Other than high mortality, adverse consequences such as mental retardation, vision loss or impairment, hearing impairment and speech impediment of NM in surviving neonates are also a major medical concern $[7,8]$.

Plasticity of $E$. coli genomes has led to the development of different pathovars of $E$. coli each of which is associated with a particular form of animal and/or human disease [9,10]. Genomic plasticity of $E$. coli is mainly due to the acquisition of 'genomic islands' through horizontal gene 
transfer by means of plasmids, phages and insertion sequences (IS) [9]. Of these elements, bacterial plasmids are self-replicating extra-chromosomal genetic materials which have the potential to transmit a variety of phenotypic characteristics among the same or different species of bacteria [9-11]. These phenotypic characteristics include novel metabolic capabilities, antibiotic resistance, heavy metal tolerance, virulence traits that are important for bacterial adherence, invasion and survival in host tissues [10,11]. Plasmid that encodes such phenotypic characteristics may provide competitive advantages to the bacterium for survival and adaptation to novel niches.

Many virulence associated plasmids have been identified in pathogenic E. coli $[10,12-14]$. A vast majority of these plasmids belong to IncF compatibility group. Structurally, IncF plasmids consist of a conserved region common to all IncF plasmids which encodes conjugal transfer proteins, replication proteins and plasmid stability proteins and a 'genetic load region' or a variable region that encodes various virulence and fitness traits. A recent study that analyzed over 40 completed genomic sequences of IncF plasmids of $E$. coli revealed that these plasmids have evolved as virulence plasmids by acquiring novel virulence traits to their 'genetic load regions' through IS-mediated site specific recombination [10]. Also, comparative genomic analysis of virulence plasmids in each pathovar of $E$. coli has shown that these genetic load regions encode virulence traits that are essential for and specific to their respective pathotype [10]. These data suggest that acquisition of plasmid-encoded genes may play a significant role in the emergence of pathogens and different pathotypes of $E$. coli.

Although many virulence-associated plasmids in various intestinal pathogenic $E$. coli have been sequenced and studied, only a few virulence plasmids associated with each pathotype of extra-intestinal pathogenic E. coli (ExPEC) causing human infection have been sequenced [10]. For example, at the time of preparing this manuscript, only two plasmid sequences from NMEC strains were available in the public domain $[14,15]$. These two strains represent two of three major serogroups of E. coli (O18, O45 and O7) that have been implicated in NM; pECOS88 from $E$. coli S88 (O45:K1) and pEC10A-D from E. coli CE10 (O7: K1). Despite the fact that the NMEC prototypic strain RS218 belonging to O18 serogroup is the most commonly used E. coli strain to study NMEC pathogenesis since 1980 's, its genomic sequence including the plasmid, has not been reported [16]. It has been documented that the NMEC RS218 strain harbors a large plasmid and similar sized plasmids have been observed in other NMEC and avian pathogenic E. coli (APEC) belonging to the $\mathrm{O} 18$ serogroup $[17,18]$.

Therefore, the objectives of the present study were to: (i) analyze the nucleotide sequence of pRS218 and its genetic and evolutionary relationship with virulence-associated plasmids in other pathogenic E. coli, (ii) analyze the distribution of pRS218 genes among NMEC, and (iii) evaluate the contribution of pRS218 to NMEC pathogenesis by comparing the virulence of plasmid-cured and wild-type strains in vitro and in vivo.

\section{Results}

\section{General properties of pRS218}

Initial de novo assembly of short reads generated with Ion Torrent PGM technology identified 26 plasmid contigs ranging from 253 to 7,521 bp in length. These contigs were aligned to the reference plasmid sequence pUTI89 of uropathogenic E. coli strain UTI89 which was selected as the reference according to the sequence similarity of contigs (>90\%). Complete sequence of pRS218 revealed that it is a circular plasmid of $114,231 \mathrm{bp}$ in size with a $\mathrm{G}+\mathrm{C}$ content of $51.02 \%$ (Figure 1). A total of one hundred and sixty open reading frames (ORFs) were annotated including IncFIB and FIIA replicons. Based on the blast analysis, nearly one third of the ORFs $(n=51)$ represents the genes involved in plasmid replication and conjugal transfer, along with 20 and 7 genes encoding mobile genetic elements (MGEs) and products involved in DNA repair, respectively. Of the remaining ORFs, 59 encode unknown or hypothetical proteins, and 23 represent genes previously characterized in other bacteria. The plasmid does not harbor any antibiotic resistance genes that may provide a selective advantage in the face of antibiotic therapy. Genetic load region of the pRS218 encodes several virulence- and fitness-associated genes which have been reported in other bacteria (Table 1). The annotated sequence of pR218 was deposited in GenBank at the NCBI [GenBank: CP007150].

\section{pRS218 is remarkably similar to plasmids of $E$. coli strains that cause cystitis}

The BLAST nucleotide algorithm (blastn) showed that pRS218 is $99 \%$ identical to plasmids pUTI89 [GenBank:CP000244], p1ESCUM [GenBank:CU928148] and pEC14_114 [GenBank:GQ398086] of E. coli causing acute cystitis, pUM146 [GenBank:CP002168] of a strain of E. coli associated with Crohn's disease, and pECSF1 [GenBank:AP009379] of an E. coli strain belonging to the phylogenetic group B2 which was isolated from feces of a healthy adult (Figure 2) [23]. Analysis of the repA1 sequence of FIIA replicon of 24 IncFIB/IIA plasmids in pathogenic $E$. coli revealed three main lineages of virulence plasmids (Figure 3). All NMEC virulence plasmids were clustered into one lineage based on the repA1 sequence suggesting a common origin. Interestingly, pRS218 showed an identical origin with several virulence plasmids of E. coli causing cystitis (pUTI89 and pEC14_114), pECSF1 of the commensal phylogenetic group B2 E. coli strain SE15 and PCE10A of NMEC strain CE10. 


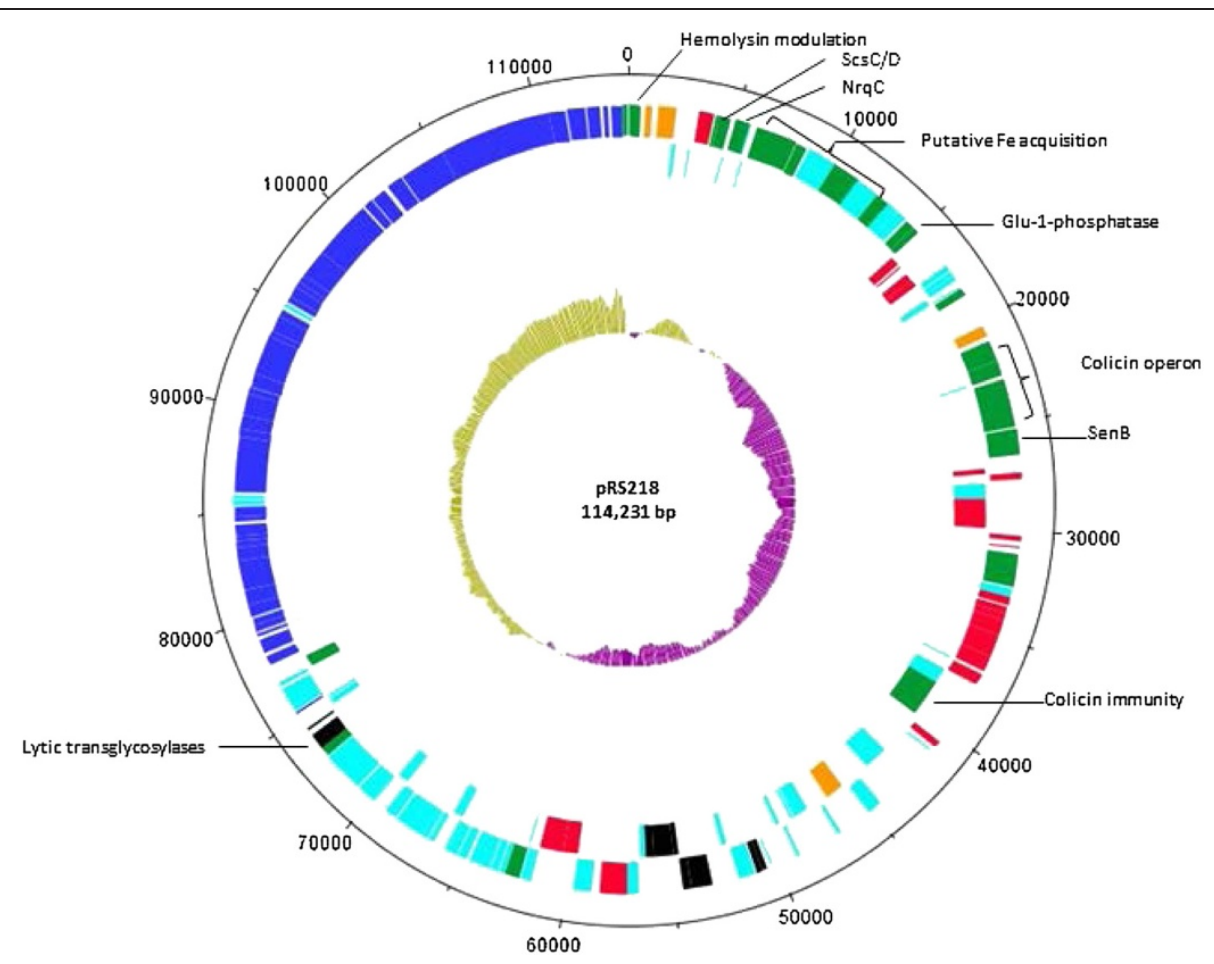

Figure 1 Graphical circular map of pRS218. From outside to the center: ORFs in forward strand, ORFs in reverse strand, and GC skew. Plasmid genes are color coded as follows: Blue, conjugal transfer genes; Green, virulence or fitness-associated genes; Orange, plasmid replication genes; Red, IS elements; Black, plasmid stability genes; Light blue, hypothetical and putative genes. In the GC skew lime indicates the areas where the GC skew above average (51\%) and purple indicates the areas below average.

\section{Genes of pRS218 are overly represented in NMEC strains} compared to fecal $E$. coli

Plasmid profiling revealed 27 of 53 (51\%) of NMEC strains examined in the study harbored a plasmid similar in size to pRS218 (130-100 kb) (Table 2). Furthermore, PCR analysis revealed that a vast majority of pRS218associated genes tested $(n=59)$ were overly represented
( $\mathrm{n}=52$ ) among NMEC strains as compared to commensal E. coli (Table 3).

Plasmid-cured strain demonstrated a marked attenuation in vitro and in vivo

To analyze the virulence potential of pRS218, the plasmid was cured from the wild type strain by mutating $s t b A$

Table 1 Virulence and fitness-associated genes located on the genetic load region of pRS218

\begin{tabular}{|c|c|c|c|}
\hline Gene name & Virulence/fitness-associated traits & Function & Reference \\
\hline pRS218_010 & Putative Na-translocating NADH dehydrogenase & $\mathrm{Na}^{+}$efflux (NrqC subunit) & {$[19]$} \\
\hline$\overline{\text { pRS218_013 }}$ & High affinity $\mathrm{Fe}^{2+}$ permease & Iron acquisition & [13] \\
\hline pRS218_014 & High affinity $\mathrm{Fe}^{2+}$ periplasmic component & Iron acquisition & [13] \\
\hline pRS218_015 & High affinity $\mathrm{Fe}^{2+}$ protein, membrane component & Iron acquisition & [13] \\
\hline pRS218_016 & High affinity $\mathrm{Fe}^{2+}$ binding protein, permease & Iron acquisition & [13] \\
\hline pRS218_017 & Putative $A B C$ transport sys, permease & Type I secretion & [13] \\
\hline pRS218_018 & Putative ABC transport system, ATP-binding & Type I secretion & [13] \\
\hline pRS218_019 & TonB-dependent heme/hemoglobin receptor & Iron acquisition & [13] \\
\hline pRS218_039 & $\operatorname{Sen} B$ & Enterotoxin in EIEC/Shigella & [26] \\
\hline pRS218_001 & Putative GTP binding protein, YihA & Cell signaling and membrane ruffling & [20] \\
\hline pRS218_190 & Hemolysin expression modulating protein & Thermo-osmotic regulation of hly & [13] \\
\hline pRS218_007 & Suppressor for copper sensitivity ScsC/ScsD & Copper tolerance & [25] \\
\hline pRS218_022 & Glucose-1-phosphatase & Virulence regulator & [21] \\
\hline pRS218_116 & Lytic transglycosylases & Cell division & [22] \\
\hline
\end{tabular}




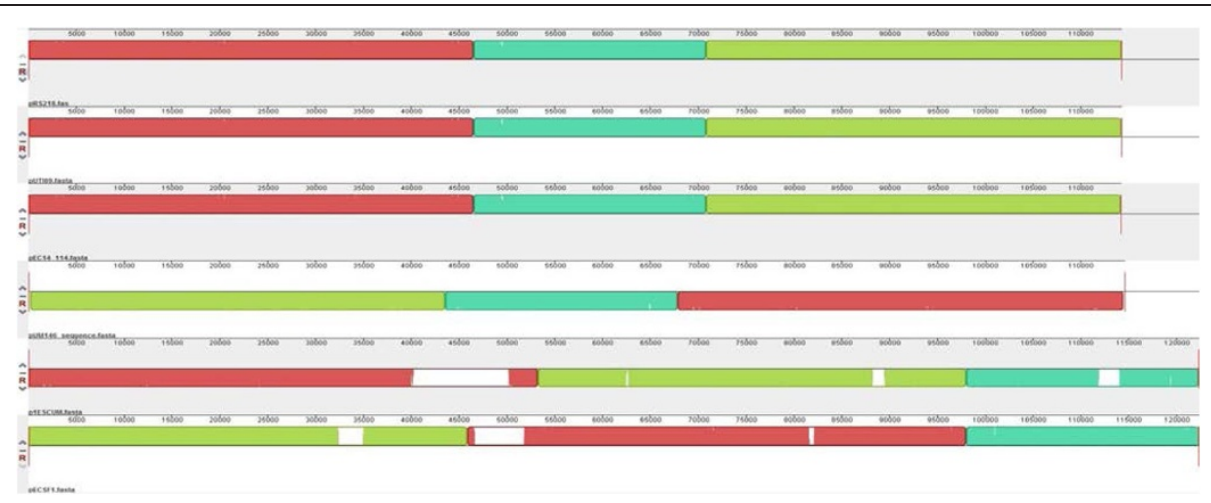

Figure 2 Comparison of pRS218 sequence to some virulence plasmids of other E. coli. Each code indicates a plasmid sequence. From top to bottom; pRS218, pUTI89 (a plasmid of the acute cystitis causing E. coli strain UT189), pEC14_114 (a plasmid of the uropathogenic E. coli strain EC14), pUM146 (a plasmid of the adherent invasive E. coli strain UM146), p1ESCUM (a plasmid of the acute cystitis causing E. coli strain UMN026) and PECSF1 (a plasmid of the commensal E. coli strain SE15). Each color box indicates clusters of ortholog genes present in plasmid sequences. White spaces in the blocks indicate the sequences that are not present in other plasmid sequences.

followed by $10 \%$ SDS treatment. Curing of plasmid was confirmed by the absence of the plasmid in the purified plasmid preparation and the absence of 5 selected genes of pRS218 by PCR in a crude DNA extract made from the plasmid-cured strain $\left(\right.$ RS218 $8_{\text {cured) }}$. Figures $4 \mathrm{~A}$ and B show the plasmid profiles and PCR amplification results of wild-type RS218 (wtRS218) and plasmid-cured RS218 $\left(\mathrm{RS} 218_{\text {cured }}\right)$. No difference was observed in the growth rates between wtRS218 and RS218 $8_{\text {cured }}$ (Figure 4C). Virulence potential of pRS218 was determined by comparing

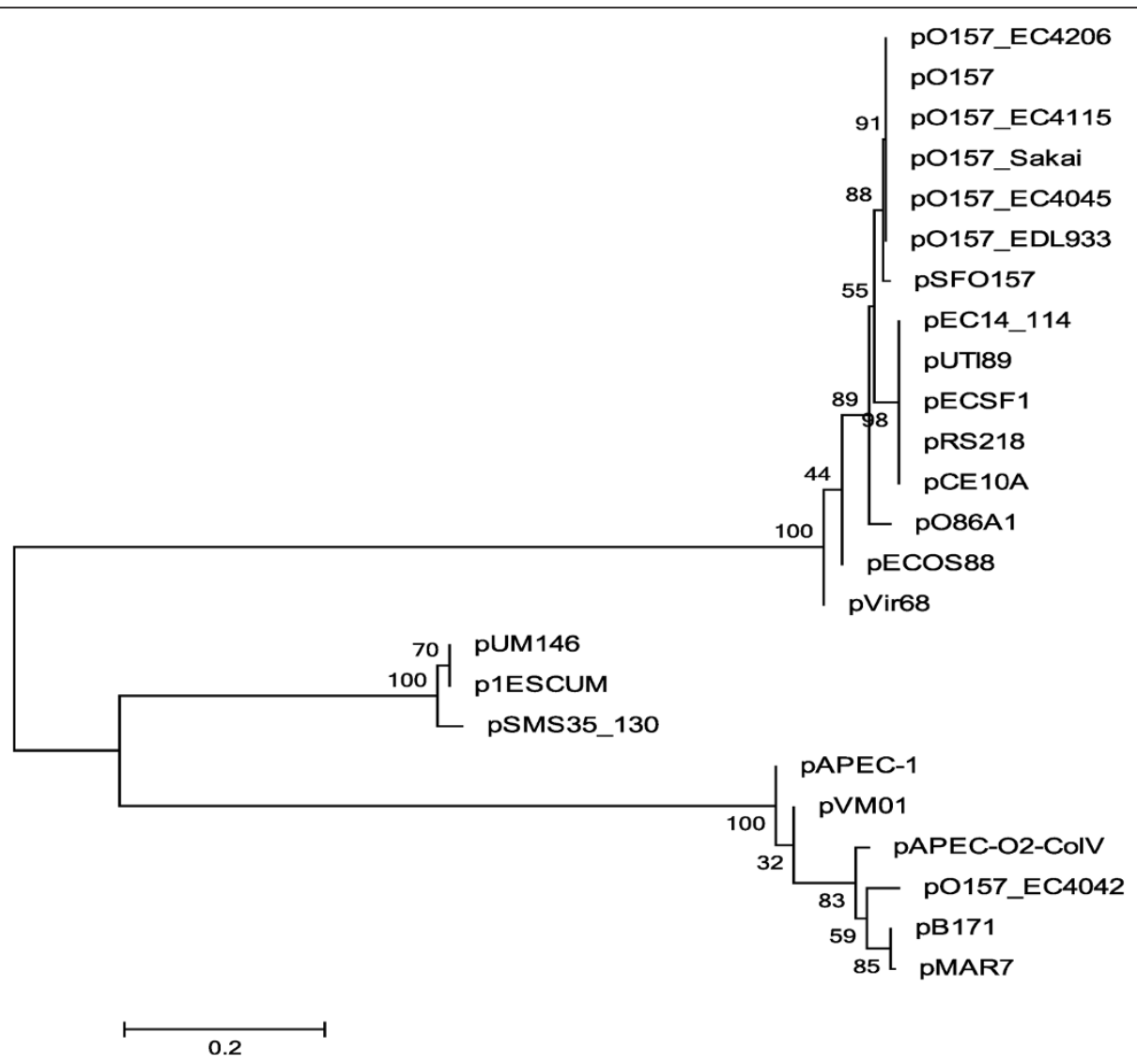

Figure 3 Evolutionary relationship of IncFIB/IIA plasmids in pathogenic $E$. coli based on the repA1 sequence. The percentage of replicate trees in which the associated taxa clustered together in the bootstrap test (500 replicates) is shown next to the branches. 
Table 20 serogroups of neonatal meningitis causing E. coli strains carrying pRS218-like plasmids

\begin{tabular}{|c|c|c|}
\hline Isoate \# & O serogroup & $\begin{array}{l}\text { Plasmids similar in size to } \\
\text { pRS218 +, present; -, absent }\end{array}$ \\
\hline NMEC1 & 18 & - \\
\hline NMEC2 & 75 & - \\
\hline NMEC3 & 2 & - \\
\hline NMEC4 & Multiple & + \\
\hline NMEC5 & 25 & - \\
\hline NMEC6 & 15 & - \\
\hline NMEC7 & 8 & - \\
\hline NMEC8 & 11 & + \\
\hline NMEC9 & Negative & + \\
\hline NMEC10 & 92 & + \\
\hline NMEC11 & Negative & + \\
\hline NMEC12 & 18 & + \\
\hline NMEC13 & 6 & - \\
\hline NMEC14 & 8 & - \\
\hline NMEC15 & 12,16 & + \\
\hline NMEC16 & 1 & + \\
\hline NMEC17 & 12,16 & + \\
\hline NMEC18 & 6 & + \\
\hline NMEC19 & Multiple & + \\
\hline NMEC20 & 8 & - \\
\hline NMEC21 & 19 & - \\
\hline NMEC22 & 18 & + \\
\hline NMEC23 & 75 & - \\
\hline NMEC24 & 107 & - \\
\hline NMEC25 & 1 & + \\
\hline NMEC26 & 8 & + \\
\hline NMEC27 & 8 & + \\
\hline NMEC28 & Multiple & + \\
\hline NMEC29 & 16 & + \\
\hline NMEC30 & 5 & - \\
\hline NMEC31 & 8 & - \\
\hline NMEC32 & 75 & - \\
\hline NMEC33 & 2 & + \\
\hline NMEC34 & 16 & - \\
\hline NMEC35 & 2 & + \\
\hline NMEC36 & Multiple & - \\
\hline NMEC37 & 21 & - \\
\hline NMEC38 & 1 & + \\
\hline NMEC39 & 1 & + \\
\hline NMEC40 & 1 & + \\
\hline NMEC41 & 18 & - \\
\hline NMEC42 & 18 & - \\
\hline NMEC43 & 7 & + \\
\hline NMEC44 & 78 & + \\
\hline NMEC45 & 25 & - \\
\hline
\end{tabular}

Table 20 serogroups of neonatal meningitis causing E. coli strains carrying pRS218-like plasmids (Continued)

\begin{tabular}{lcl}
\hline NMEC46 & 1 & + \\
\hline NMEC47 & 1 & - \\
\hline NMEC48 & 1 & - \\
\hline NMEC49 & Negative & - \\
\hline NMEC50 & 1 & - \\
\hline NMEC51 & 18 & + \\
\hline
\end{tabular}

RS218 $8_{\text {cured }}$ with wtRS218 based on their ability to invade human cerebral microvascular endothelial (hCMEC/D3) cells in vitro and to cause septicemia, meningitis and mortality in vivo in a rat pup model of neonatal meningitis. In vitro invasion assays using hCMEC/D3 cells revealed a significant attenuation $(\mathrm{p}<0.05)$ of $\mathrm{RS} 218_{\text {cured }}$ (relative invasion $38 \pm 9.6 \%$ ) as compared to the wild type strain (100\%) (Figure 5A). Furthermore, invasiveness was restored after complementation of RS218 $8_{\text {cured }}$ strain with the pRS218 indicating its contribution to NMEC pathogenesis. Similar results were observed with the in vivo experiments as well. Although fewer pups died within $24 \mathrm{hrs}$ post-infection in the groups infected with RS218 $8_{\text {cured }}$ as compared to the groups infected with wtRS218 and RS218 ${ }_{\text {compl }}$, there was no statistically significant difference in mortality rates between the three groups (Figure 5B). No mortalities were detected in the negative control group treated with $\mathrm{PBS}$ or $E$. coli DH5 $\alpha$. In groups infected with wtRS218 or RS218 $8_{\text {compl }}$, $84-87 \%$ of rat pups that survived 24 hrs post-infection showed septicemia, whereas in groups treated with RS218 $8_{\text {cured }}$ strain, only 33\% had septicemia. In all three groups the number of bacteria in the blood was too numerous to count $\left(>1.5-2.8 * 10^{4} \mathrm{CFU} / \mathrm{ml}\right)$. Also, $E$. coli were re-isolated from CSF collected from $84-87 \%$ of rat pups infected with wtRS218 or RS218 whereas only $29 \%$ CSF samples collected from rat pups infected with RS218 $8_{\text {cured }}$ strain contained $E$. coli suggesting a role of pRS218 in translocation of bacteria through the blood brain barrier (BBB) to cause meningitis. Similarly, histopathological evaluation of brain tissue from the rat pups inoculated with wRS218 or RS218 $8_{\text {compl }}$ strains demonstrated lesions consistent with meningitis (Figure 6). The bacterial loads in CSF were $4.57+3.02 * 10^{3}$ in rat pups infected with wtRS218 strain and $3.77+2.24 * 10^{3}$ in rat pups infected with RS218 $8_{\text {cured }}$ strain.

\section{Discussion}

Virulence plasmids in bacterial pathogens have been shown to play a major role in pathogenesis of many bacterial diseases $[10,12,24,25]$. In pathogenic $E$. coli, virulenceassociated large plasmids that are required to establish distinct disease phenotypes have been characterized using 
Table 3 Prevalence of pRS218 genes among neonatal meningitis causing $E$. coli and fecal commensal $E$. coli strains

\begin{tabular}{|c|c|c|c|c|c|c|}
\hline Gene name & Predicted function & NMEC \% & FEC $\%$ & Chi squire value & $P$ value & Related pUTI89 locus \\
\hline pRS218_007 & Copper sensitivity & 98.11 & 46.94 & 65.229 & $<0.0001$ & P007 \\
\hline pRS218_008 & Copper sensitivity & 96.23 & 22.45 & 113.187 & $<0.0001$ & P008 \\
\hline pRS218_010 & $\mathrm{Na}+$ traslocation & 100.00 & 18.37 & 133.182 & $<0.0001$ & P009 \\
\hline pRS218_013 & Iron permease & 98.11 & 28.57 & 105.105 & $<0.0001$ & P010 \\
\hline pRS218_014 & Iron transport & 100.00 & 57.14 & 51.864 & $<0.0001$ & P011 \\
\hline pRS218_015 & Membrane protein & 96.23 & 18.37 & 124.113 & $<0.0001$ & P012 \\
\hline pRS218_016 & $A B C$ transporter & 100.00 & 24.49 & 117.051 & $<0.0001$ & P013 \\
\hline pRS218_017 & Membrane protein & 94.34 & 77.55 & 12.706 & 0.0004 & P014 \\
\hline pRS218_018 & $\mathrm{ABC}$ transporter & 98.11 & 55.10 & 51.425 & $<0.0001$ & P015 \\
\hline pRS218_019 & Putative thioredoxin precursor & 83.02 & 18.37 & 20.529 & $<0.0001$ & P016 \\
\hline pRS218_020 & Hypothetical protein & 100.00 & 18.37 & 133.182 & $<0.0001$ & P017 \\
\hline pRS218_022 & Glucose-1-phosphatase & 100.00 & 75.51 & 24.428 & $<0.0001$ & P018 \\
\hline pRS218_023 & Glucose-1-phosphatase & 98.11 & 16.33 & 137.169 & $<0.0001$ & P018 \\
\hline pRS218_031 & Hypothetical protein & 98.11 & 26.53 & 107.541 & $<0.0001$ & P024 \\
\hline pRS218_034 & Colicin immunity & 84.91 & 91.84 & 2.407 & 0.1208 & P023 \\
\hline pRS218_035 & ColicinJ production & 66.04 & 100.00 & 49.668 & $<0.0001$ & P027 \\
\hline pRS218_036 & ColicinJ production & 77.36 & 97.96 & 20.16 & $<0.0001$ & P028 \\
\hline pRS218_038 & ColicinJ production & 100.00 & 26.53 & 112.012 & $<0.0001$ & P029 \\
\hline pRS218_039 & Enterotoxin & 100.00 & 71.43 & 33.918 & $<0.0001$ & P030 \\
\hline pRS218_042 & Hypothetical protein & 98.11 & 44.90 & 68.924 & $<0.0001$ & P034 \\
\hline pRS218_056 & Hypothetical protein & 100.00 & 6.12 & 177.358 & $<0.0001$ & P042 \\
\hline pRS218_057 & ColicinJ production & 100.00 & 100.00 & 0 & 1 & P043 \\
\hline pRS218_060 & Hypothetical protein & 96.23 & 10.20 & 148.454 & $<0.0001$ & P045 \\
\hline pRS218_063 & Hypothetical protein & 100.00 & 24.49 & 120 & $<0.0001$ & P051 \\
\hline pRS218_064 & Hypothetical protein & 100.00 & 0.00 & 197.04 & $<0.0001$ & P052 \\
\hline pRS218_073 & Hypothetical protein & 94.34 & 53.06 & 43.152 & $<0.0001$ & P060 \\
\hline pRS218_074 & Stability protein StbA & 90.57 & 20.41 & 102.055 & $<0.0001$ & P062 \\
\hline pRS218_079 & Hypothetical protein & 98.11 & 22.45 & 120.333 & $<0.0001$ & P042 \\
\hline pRS218_080 & Unknown & 100.00 & 100.00 & 0 & 1 & P065 \\
\hline pRS218_082 & Hypothetical protein & 100.00 & 34.69 & 96.296 & $<0.0001$ & P068 \\
\hline pRS218_083 & Transposase & 98.11 & 22.45 & 120.333 & $<0.0001$ & P071 \\
\hline pRS218_086 & Hypothetical protein & 98.11 & 22.45 & 120.333 & $<0.0001$ & P072 \\
\hline pRS218_088 & Adenine-specific methyltransferase & 100.00 & 13.33 & 151.027 & $<0.0001$ & P074 \\
\hline pRS218_089 & Cytoplasmic protein & 83.02 & 73.47 & 2.914 & 0.0878 & P075 \\
\hline pRS218_090 & Hypothetical protein & 30.19 & 48.98 & 7.553 & 0.006 & P076 \\
\hline pRS218_091 & Hypothetical protein & 98.11 & 55.10 & 51.425 & $<0.0001$ & P078 \\
\hline pRS218_091 & Hypothetical protein & 100.00 & 36.73 & 91.971 & $<0.0001$ & P078 \\
\hline pRS218_092 & Putative antirestriction protein & 73.58 & 83.67 & 3.014 & 0.0826 & P079 \\
\hline pRS218_093 & Phage protein MubC & 100.00 & 81.63 & 16.986 & $<0.0001$ & P080 \\
\hline pRS218_094 & Hypothetical protein & 98.11 & 57.14 & 48.201 & $<0.0001$ & P081 \\
\hline pRS218_095 & Hypothetical protein & 75.47 & 6.12 & 98.786 & $<0.0001$ & P083 \\
\hline pRS218_099 & Hypothetical protein & 90.57 & 34.69 & 67.267 & $<0.0001$ & P088 \\
\hline pRS218_100 & Hypothetical protein & 100.00 & 34.69 & 96.296 & $<0.0001$ & P089 \\
\hline pRS218_105 & Cytoplasmic protein & 75.47 & 93.88 & 13.781 & 0.0002 & P093 \\
\hline pRS218_106 & Hypothetical protein & 96.23 & 32.65 & 86.669 & $<0.0001$ & P094 \\
\hline pRS218_107 & Adenine-specific methyltransferase & 100.00 & 32.65 & 100.086 & $<0.0001$ & P095 \\
\hline pRS218_109 & Hok/Gef cell toxic protein & 100.00 & 93.88 & 0 & 0.9944 & P097 \\
\hline
\end{tabular}


Table 3 Prevalence of pRS218 genes among neonatal meningitis causing $E$. coli and fecal commensal E. coli strains (Continued)

\begin{tabular}{|c|c|c|c|c|c|c|}
\hline pRS218_110 & Hypothetical protein & 98.11 & 26.53 & 107.541 & $<0.0001$ & P099 \\
\hline pRS218_113 & Hypothetical protein & 100.00 & 83.67 & 17.391 & $<0.0001$ & P100 \\
\hline pRS218_113 & Hypothetical protein & 100.00 & 73.47 & 31.214 & $<0.0001$ & P100 \\
\hline pRS218_114 & Unknown & 100.00 & 44.90 & 72.93 & $<0.0001$ & P101 \\
\hline pRS218_116 & X polypeptide & 97.96 & 46.94 & 65.229 & $<0.0001$ & P102 \\
\hline pRS218_118 & TraJ/conjugal transfer & 43.40 & 10.20 & 27.955 & $<0.0001$ & P104 \\
\hline pRS218_131 & Hypothetical protein & 100.00 & 93.88 & 6.186 & 0.0129 & P116 \\
\hline pRS218_136 & TraU/conjugal transfer & 100.00 & 42.86 & 79.72 & $<0.0001$ & P120 \\
\hline pRS218_154 & Tral/conjugal transfer & 81.13 & 53.06 & 17.73 & $<0.0001$ & P138 \\
\hline pRS218_156 & Dienelactone hydrolase & 90.57 & 73.47 & 20.195 & $<0.0001$ & P141 \\
\hline pRS218_159 & Hypothetical protein & 90.57 & 93.88 & 1.087 & 0.2971 & P144 \\
\hline pRS218_190 & Hemolysin expression modulating protein & 90.57 & 12.24 & 124.932 & $<0.0001$ & P145 \\
\hline
\end{tabular}

$P<0.05$ indicates a statistical significance.

in vitro and in vivo studies [10,12-14,17,25]. Recently, it has been suggested that the plasmids may play a role in NMEC pathogenesis since most of the NMEC strains harbor plasmid-associated genes as compared to commensal E. coli [26]. Escherichia coli RS218 which was isolated from CSF of a neonate with meningitis in 1974 is considered as the prototype strain of NMEC. This strain has been used in the studies since then to identify the virulence traits that are particularly involved in NMEC pathogenesis [16]. Here, we determined and analyzed the complete nucleotide sequence of pRS218, a large plasmid of E. coli RS218, and studied its contribution to the NMEC pathogenesis.

The pRS218 sequence revealed a backbone typical to IncFIB/IIA-like plasmids in other pathogenic $E$. coli which possess both repA and repA1 replicons [10]. In addition to the replication proteins, the constant region of the plasmid encodes proteins involving conjugal transfer (Tra locus) and plasmid stability/inheritance. The tra locus comprises $34.9 \mathrm{~kb}$ region containing 34 tra genes from traM to finO similar to F-like plasmids of E.coli and R100 plasmid of Shigella [27]. The plasmid SOS inhibition protein (PsiAB), plasmid stabilizing proteins $\mathrm{Stb} A B$ and $\mathrm{Ccd} A B$, toxin-antitoxin proteins involved in post segregation killing are also present in the constant region that confers stability and inheritance of the plasmid in progeny cells. Parallel to these findings, we have observed that the curing of pRS218 is very difficult with chemical methods such as ethidium bromide and SDS treatment alone. Therefore, we mutated the $s t b A$ gene which has been identified as an essential gene for stable inheritance of IncF plasmids to achieve successful curing of pRS218 from E. coli RS218.

Genetic load region or the variable region of the pRS218 contains IS elements, virulence-associated genes, and several putative and hypothetical genes. The pRS218 contains 20 IS elements belonging to twelve different types. Previous studies have shown that IS-mediated recombination might play a major role in acquiring novel genes into plasmids thereby allowing the plasmid to act as a "pathogenicity island precursor" [10,12,14]. Interestingly, IS elements of pRS218 are located upstream or downstream of virulence/fitness-associated genes in genetic load regions providing further evidence for such speculation (Figure 1). Types of virulence or fitness genes in the genetic load region of pRS218 are depicted in Table 1 and are mainly located upstream and downstream of IncFIB replicon. Upstream to the IncFIB replicon, are the secreted copper-sensitivity suppressor proteins $C$ and $\mathrm{D}(\operatorname{scs} C$ and $\operatorname{scs} D)$. Copper is an essential trace element required for bacterial growth and it acts as a toxic compound if available in excess. Antibacterial properties of ionic copper have been studied and used in hospital settings to prevent nosocomial infections [28]. The pRS218 encoded $s c s C$ and $s c s D$ are identical to copper suppressor proteins in the genomic island GI-DT12 of Salmonella enterica subsp. enterica serovar Typhimurium str. T000240 which have been studied in relation to conferring copper resistance in recombinant $E$. coli carrying GI-DT12 providing a fitness advantage to the pathogen [29]. Additionally, this region encodes several iron acquisition proteins, hemoglobin receptors and a putative $\mathrm{ABC}$ transporter which may be involved in the survival of bacteria in an iron-limited milieu inside the host. Furthermore, pRS218 also encodes an enterotoxin called SenB, which has been found in enteroinvasive E. coli and Shigella spp and accounts for $50 \%$ of their enterotoxic activities [30]. Interestingly, nucleotide blasting of $\operatorname{sen} B$ sequence reveled that it is also present in the genomes of E. coli CE10 and the Citrobacter koseri which are associated with meningitis in newborns. Moreover, $\operatorname{sen} B$ is located just downstream of cjr operon which is an iron- and 


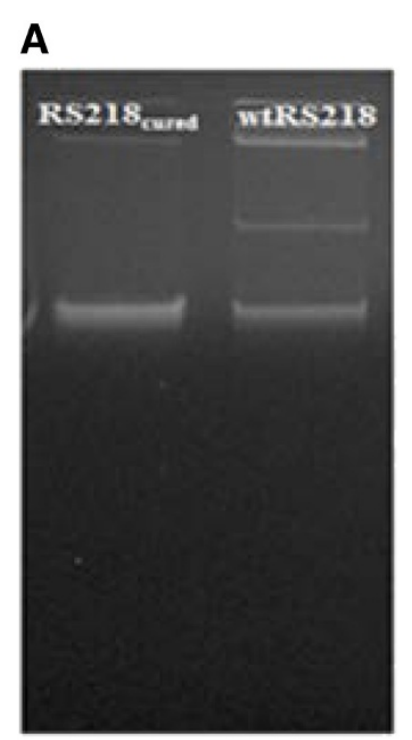

B
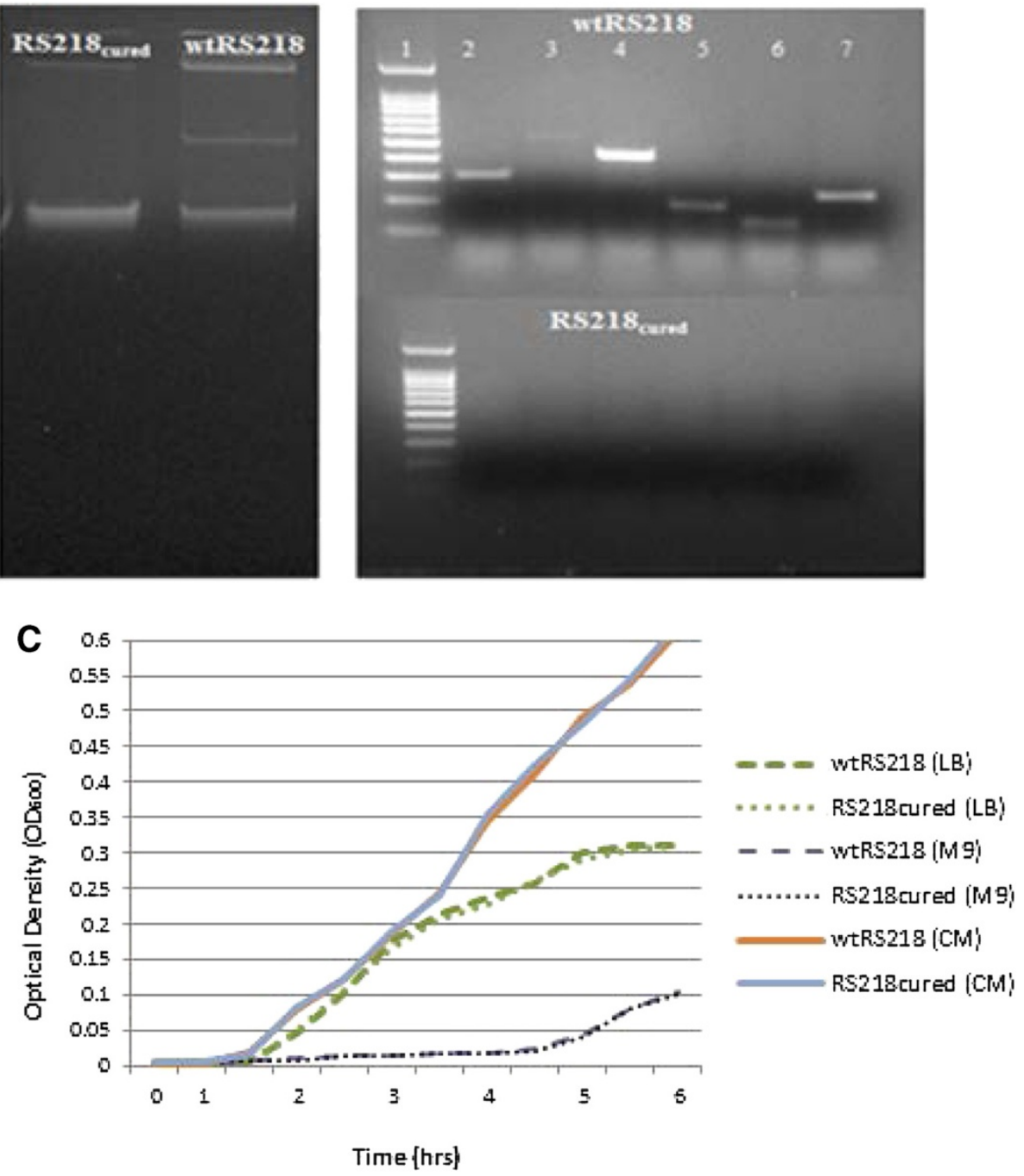

(hrs]

Figure 4 Confirmation of pRS218 curing. A, Plasmid profiles of wtRS218 and RS218 cured. B, PCR amplification of selected pRS218 genes in wtRS218 and RS218 cured. Lane 1,100 bp ladder; Lane 2, senB; Lane 3, scsD; Lane 4, transposase; Lane 5, traU; Lane 6, pRS218_113; Lane 7, ycfA; Lane 8, ompA. C, Growth of wtRS218 and RS218 cured E. coli in LB broth, M9 medium containing $10 \mu \mathrm{g} / \mathrm{ml}$ niacin broth (M9), and complete cell culture medium (CM).

temperature-regulated operon expressed only during the pathogenic process of $E$. coli suggesting that $\operatorname{sen} B$ may be involved in NMEC pathogenesis [30]. A recent study reported that mutation of $c j r$ area of pUTI89 (which is $>99 \%$ similar to pRS218) significantly decreased bacterial invasion and intra-cellular bacterial community (IBC) formation in infected bladders [12]. However, the association of pRS218-encoded traits such as SenB in NMEC penetration of the intestinal epithelium and iron acquisition systems in NMEC survival within the host are yet to be identified. Other than these putative virulenceassociated genes, many hypothetical proteins of unknown functions are present both upstream and downstream of IncFIB replicon.
Furthermore, we screened 59 pRS218 genes among 53 NMEC strains and fecal E. coli strains isolated from healthy individuals. A vast majority of pRS218-associated genes tested were overly represented among NMEC strains as compared to commensal E. coli (Table 3) suggesting a relationship between the presence of pRS218 genes and the NMEC pathotype. These overly represented genes included several hypothetical proteins and virulenceassociated genes present in pRS218 such as copper sensitivity, iron acquisition, $\mathrm{ABC}$ transporter components, traJ and $\operatorname{sen} B$.

We also analyzed the sequence similarity and the evolutionary relationship of pRS218 with other NMEC plasmids, namely pECOS88 and pCE10A, and some other 


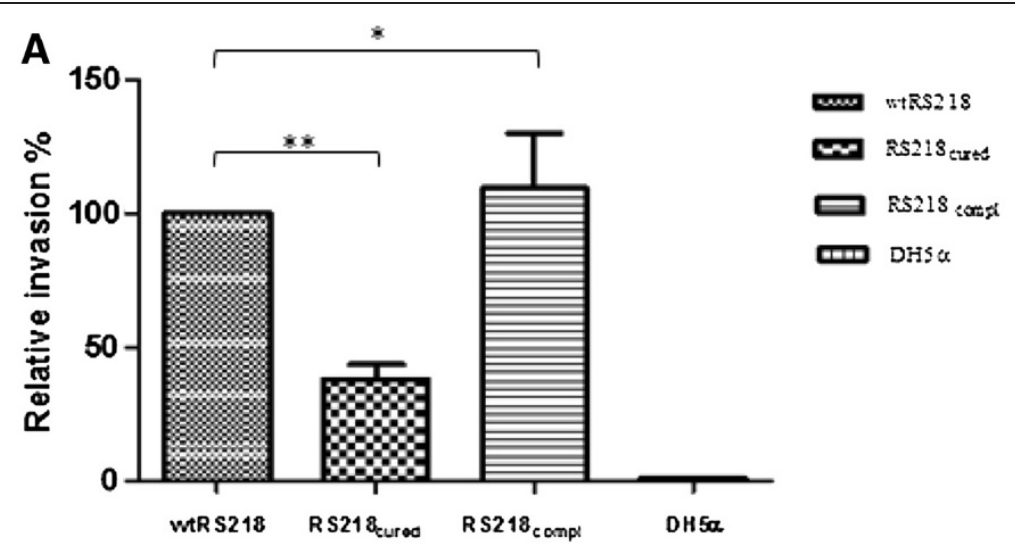

B

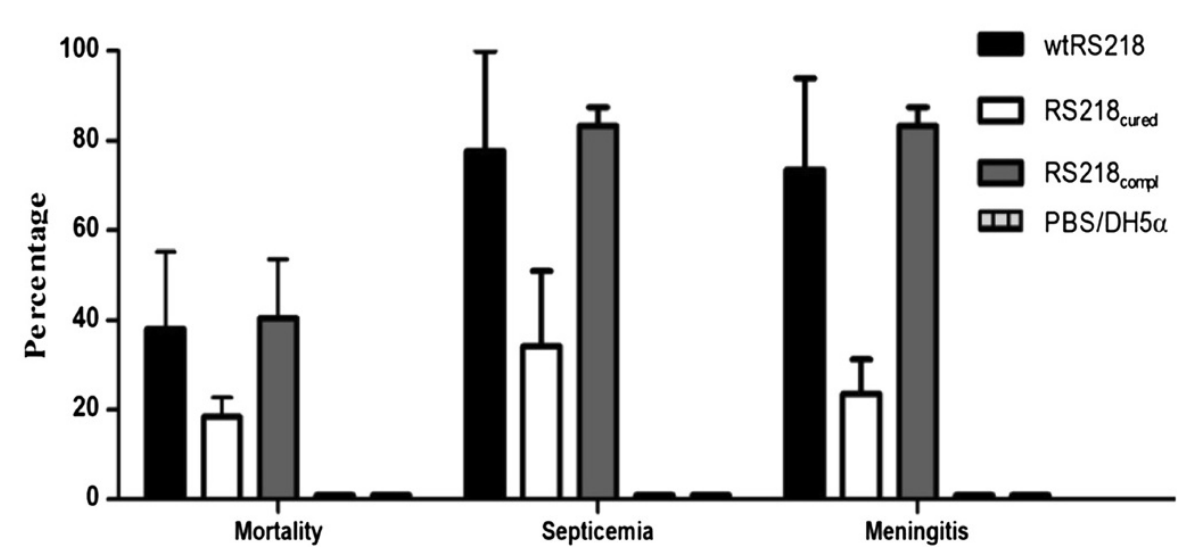

Figure 5 Evaluation of virulence potential of pRS218 in vitro and in vivo. A, Involvement of pRS218 in invasion of hCMEC cells. B, Comparison of mortality, septicemia and meningitis among the groups of rat pups infected with wtRS218, RS218 cured, $_{\text {RS218 }}$ compl. ${ }^{* *}$ denotes statistical significance and * denotes no statistical significance.

IncFIB/IIA plasmids of pathogenic E. coli (Figures 2 and 3). The pRS218 showed a remarkable sequence similarity to four plasmids found in E. coli associated with acute cystitis (pUTI89, pEC14_114, p1ESCUM, and pUMN146) and a plasmid present in an enteroinvasive $E$. coli (pECSF1) (Figure 2). The differences detected among pRS218, pUT89, pEC14_114 and pUMN146 revealed only SNPs and insertion of a tet $A B C D$ antibiotic resistance cassette in p1ESCUM and pECSF1 (Figure 2 and Table 4). However, the nucleotide sequence of pRS218 showed a marked difference from those of two NMEC plasmid sequences currently available in the public domain. For example, pECOS 88 shares similarity only with tra locus, repA and repA1 regions of pRS218 revealing that the genetic load regions of these plasmids harbor different putative virulence and hypothetical genes to those of pRS218. Compared to pECOS88, pCE10A plasmid showed a relatively higher nucleotide sequence similarity to pRS218 genetic load region containing the copper resistanceassociated genes $(\operatorname{scs} D C), \operatorname{cjr} A B C$ and $\operatorname{sen} B$. However,
pCE10A lacks the tra locus thereby making the plasmid incapable of conjugal transfer.

Among many capsular types of E. coli, $\mathrm{K} 1$ is the most common type associated with NM and according to previous studies, approximately $80 \%$ of NMEC possessed a K1 capsule $[4,5]$. Neonates acquire E. coli K1 mainly from the urogenital microflora of the mother. Although there are no studies done on the mechanisms that facilitate the vaginal epithelial colonization and survival of the NMEC strains in the urogenitary tract of women, it has been well documented that cystitis causing E. coli can survive and persist inside bladder epithelial cells as IBCs which is a dormant stage that becomes activated and shed when the immunity of the host is suppressed as is the case during pregnancy [26]. The same study has also indicated that the pUTI89 plasmid is essential for filamentation of IBCs which is the first event of reactivation of $E$. coli from the dormant state. A high degree of sequence similarity of pRS218 to other cystitis-associated plasmids and their close evolutionary relationship suggest that $E$. coli RS218 

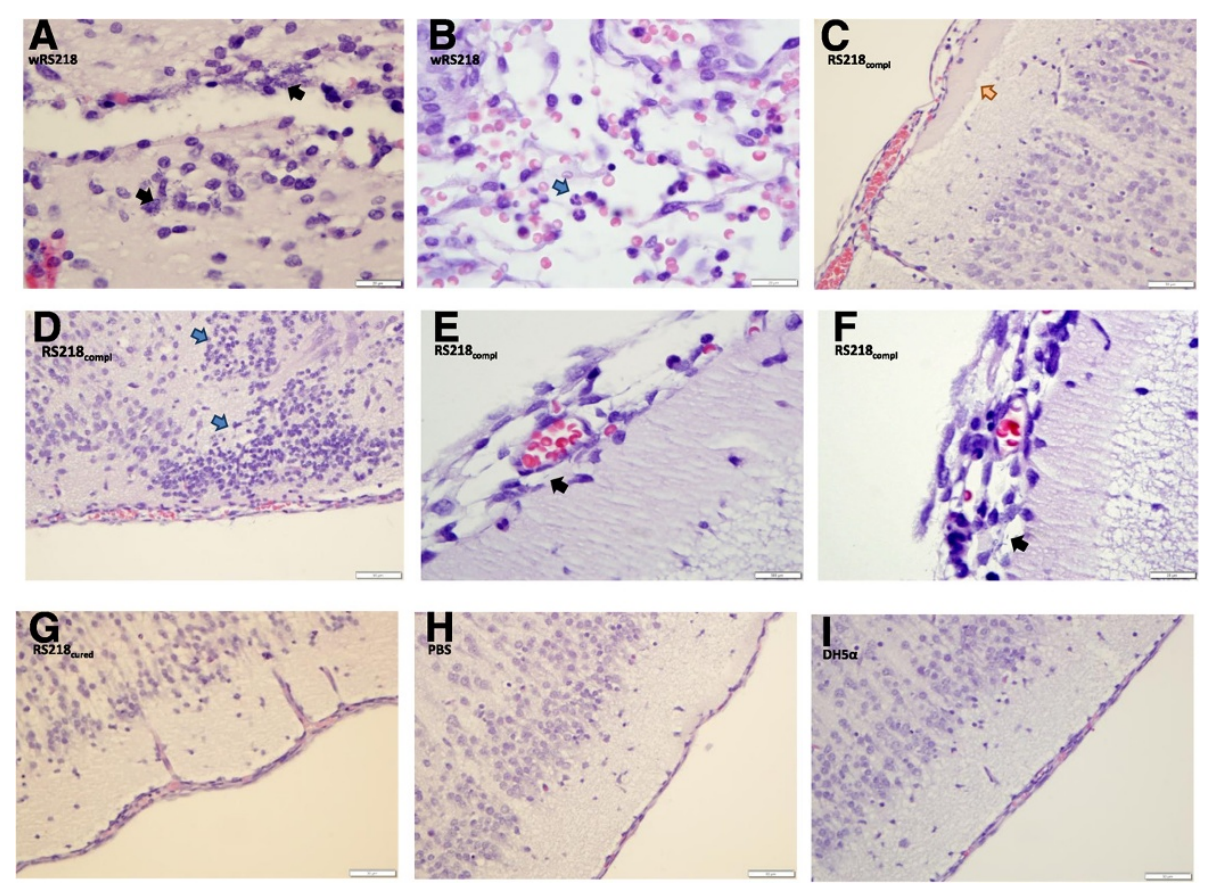

Figure 6 Histopathological evaluation of brain tissue from rat pups. Five-day-old rat pups were infected by the IP route with wtRS218,

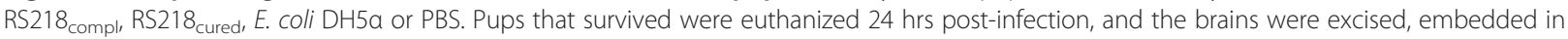
formalin, sectioned in paraffin, and stained with haematoxylin and eosin. A-F: meningitic lesions observed in pups infected with wtRS218

(A and B) or RS218 compl (C, D, E, and F). Arrows indicate rod-shaped bacteria in meninges and brain tissue (black), neutrophilic infiltration/neutrophilia (blue), and cerebral edema (orange). G to I: normal histology of brain tissue from pups inoculated with RS218 cured $_{\mathbf{G}} \mathbf{G}$ ), PBS (H) or DH5a (I).

might use the same strategy to survive in the urogenitary tract. However, the ability of E. coli RS218 to invade bladder epithelial cells and to survive within the urogenitary tract remains to be investigated.

Pathogenesis of NMEC meningitis involves three main sequential events that are governed by the virulence potential of bacteria. These include initial colonization and invasion of gastrointestinal tract, survival and multiplication in blood, and invasion of BBB [5]. We examined the pathogenic potential of pRS218 to penetrate BBB in vitro and in vivo using hCMEC/D3 cells and a rat pup model of neonatal meningitis, respectively. Curing of

Table 4 Point mutations and single nucleotide polymorphisms observed between pRS218 and pUTI89 sequences

\begin{tabular}{cccccc}
\hline pRS218 base position & pUTI89 base position & Point mutation type & pUTI89 base & pRS218 base & Gene name \\
\hline 4956 & 4956 & SNP & G & A & Intron \\
\hline 8972 & 8972 & Indel & $\mathrm{C}$ & - & Putative membrane protein \\
\hline 17429 & 17429 & Indel & - & $\mathrm{C}$ & Hypothetical Protein \\
\hline 17440 & 17439 & Indel & - & $\mathrm{C}$ & Hypothetical Protein \\
\hline 17997 & 17995 & SNP & $\mathrm{A}$ & $\mathrm{G}$ & Hypothetical Protein \\
\hline 19955 & 19953 & SNP & $\mathrm{C}$ & $\mathrm{A}$ & Intron \\
\hline 39234 & 39232 & Indel & $\mathrm{A}$ & - & Putative hemin receptor \\
\hline 39237 & 39235 & Indel & $\mathrm{T}$ & - & Putative hemin receptor \\
\hline 51720 & 51718 & SNP & $\mathrm{G}$ & $\mathrm{T}$ & Resolvase \\
\hline 53062 & 53060 & SNP & $\mathrm{C}$ & $\mathrm{T}$ & Intron \\
\hline 64393 & 64391 & Indel & $\mathrm{C}$ & - & ycfA \\
\hline 73197 & 73195 & Indel & $\mathrm{C}$ & - & psbl \\
\hline 77808 & 77806 & Indel & - & $\mathrm{A}$ & Intron \\
\hline 91272 & 91269 & SNP & $\mathrm{T}$ & $\mathrm{G}$ & trbC \\
\hline
\end{tabular}


pRS218 from E. coli RS218 did not show any effect on the growth rate revealing that differences observed between wild type and plasmid cured strains during in vitro and in vivo studies were not due to the differences in their growth rates (Figure $4 \mathrm{C}$ ).

It is believed that the high level of septicemia is a prerequisite for the penetration of BBB by NMECs to establish neonatal meningitis [4]. We observed a higher incidence of septicemia among the rat pups infected with wtRS218 strain (84\%) than the RS218 $8_{\text {cured }}$ strain indicating that plasmid-encoded genes might be involved in developing septicemia. Iron is a major limiting factor that restricts the survival and multiplication of bacteria inside the host. The genetic load region of pRS218 encodes several high affinity iron acquisition proteins, hemolysin modulation factor and hemoglobin receptor which may be involved in iron acquisition. Interestingly, these genes were highly prevalent in NMEC strains as compared to fecal E. coli (Table 3). Furthermore, in vitro and in vivo study results clearly demonstrated that RS218 $8_{\text {cured }}$ strain is far less capable of invading epithelial and endothelial cells as well as establishing meningitis in neonatal rat pups as compared to its wild type strain, suggesting that pRS218 might play a role in NMEC pathogenesis. The traJ which is present in pRS218 has been previously identified as a potential virulence trait in NMEC by signature-tagged mutagenesis and in vitro endothelial invasion assays [31]. The mutation of traJ was shown to be attenuated in terms of invasive ability to penetrate the $\mathrm{BBB}$. However, more than $50 \%$ of the NMEC strains used in this study did not possess traJ even though the gene was more prevalent in NMEC than in fecal E. coli (Table 3). The present study demonstrated that the curing of pRS218 offered a greater attenuation to RS218 strain than did the mutation of traJ alone suggesting that addtionalpRS218 genes other than traJ might be involved in NMEC pathogenesis. Interestingly, as shown in Table 3, pRS218 carries several genes that encode hypothetical proteins which are also more prevalent in NMEC than in fecal commensal E. coli. Most gene prevalence studies carried out to identify potential virulence markers of NMEC have used already known virulence genes of other ExPEC and only a limited number of studies have attempted to explore novel traits that might be helpful in defining the NMEC pathotype $[5,26,32]$. Therefore, future studies aimed at delineating the mechanistic aspects of hypothetical proteins encoded by pRS218 and are more commonly occurring in NMEC than in fecal commensal E. coli may help to close the knowledge gaps pertaining to our understanding of NMEC pathogenesis.

Although RS218 $8_{\text {cured }}$ strain was significantly attenuated in terms of in vitro (on the basis of bacterial invasion) and in vivo (on the basis of reduction in bacterial counts in CSF and blood from infected rat pups) assays as compared to the wild type strain, it was not completely avirulent. This finding suggests that the full virulence of E. coli RS218 requires both chromosomal and plasmidlocated genes. Further studies including in depth analysis of RS218 chromosome will advance our understanding of NMEC pathogenesis.

\section{Conclusions}

Incomplete understanding of NMEC pathogenesis is a major hindrance that has been identified and pointed out by many scientists particularly in relation to formulation of novel therapeutic and prevention strategies for neonatal meningitis. The plasmid pRS218 in NMEC RS218 strain belongs to IncFIB/IIA subset of virulence plasmids in pathogenic E. coli. These plasmids harbor many virulence traits that are required for bacterial survival inside the host. The nucleotide sequence of pRS218 showed a greater similarity to the plasmids of E. coli associated with acute cystitis than the plasmids from NMEC. However, the prevalence of pRS218 virulence-related genes was significantly higher in NMEC strains tested than fecal commensal $E$. coli. We have also demonstrated that the pRS218 is involved in NMEC pathogenesis using both in vivo and in vitro experiments. Future studies on pRS218 transcriptome analysis, identification of plasmidlocated genes responsible for current observations and indepth analysis of $E$. coli RS218 whole genome will likely broaden our knowledge of NMEC pathogenesis.

\section{Methods}

\section{Bacterial strains and media}

The prototype NMEC strain E. coli RS218 (O18: H7: K1) and NMEC strain EC10 (O7: K1) were kindly provided by Dr. James Johnson (Department of Medicine, University of Minnesota, Minneapolis, MN). Both E. coli RS218 and EC10 strains have been isolated from cerebrospinal fluid of neonates diagnosed with bacterial meningitis (15). A total of 51 NMEC strains which were isolated from neonatal meningitis cases were also obtained from Dr. K.S. Kim (School of Medicine, John Hopkins University, Baltimore, MD) and 49 fecal E. coli strains isolated from feces of healthy individuals were obtained from the E. coli Reference Center (Pennsylvania State University, University Park, PA). All $E$. coli were stored in Luria Bertani broth (LB) at $-80^{\circ} \mathrm{C}$ until further use. Bacteria were grown in MacConkey agar or LB broth. All bacteriologic media were purchased from Becton, Dickinson and Company (BD), Sparks, MD.

\section{Plasmid isolation, sequencing, assembly and annotation}

Sequencing of pRS218 was performed as a part of a project that sequenced the whole genome of $E$. coli RS218. The genomic DNA including the plasmid DNA was extracted using phenol-chloroform method as described 
previously [33]. The DNA preparation was further cleaned using Genomic Tips (Qiagen, Valencia, CA) [33]. Whole genome sequencing was performed using Ion Torrent PGM Technology (Life Technologies, Carlsbad, CA) at the Genomics Core Facility (Pennsylvania State University, University Park, PA). After initial de novo assembly of short reads using SeqManNGen 10 (DNASTAR Inc, Madison, WI), plasmid contigs were identified using BLAST algorithm (Blastn; www.ncbi.nlm.nih.gov) and subsequently aligned to the sequence of the reference plasmid, pUTI89 [GenBank:CP000244]. Gap closure was performed using primer walking into the gaps with the LongRange PCR Kit (Qiagen). The complete sequence of the plasmid was annotated using Rapid Annotation using Subsystem Technology (RAST) [34].

\section{Comparative genomics and phylogenetic analysis}

Comparative genomics of pRS218 with closely related IncFIB/FIIA plasmids of other $E$. coli was performed using Mauve 3.2.1 genome alignment web tool (http://gel.ahabs. wisc.edu/mauve/) [35]. An evolutionary relationship of 24 plasmids belonging to the IncFIB/FIIA group based on repA1 gene sequence was performed using the neighborjoining method. A neighbor joining tree was constructed by using the MEGA4 web tool (http://www.megasoftware. net/mega4/mega.html) [36,37].

\section{Analysis of plasmid profiles of NMEC strains}

Extraction of large plasmids from NMEC strains was performed using an alkaline lysis method described previously [33]. In brief, $1 \mathrm{ml}$ of overnight culture of each $E$. coli strain was subjected to alkaline lysis using $10 \%$ sodium hydroxide followed by phenol-chloroform extraction of plasmid DNA. Plasmid profiles of NMEC strains were evaluated by electrophoresis on a $0.7 \%$ agarose gel containing $0.5 \mu \mathrm{g} / \mathrm{ml}$ ethidium bromide.

\section{Evaluation of prevalence of selected pRS218 genes in other NMEC and fecal $E$. coli}

Specific polymerase chain reactions (PCRs) were performed to determine the presence of selected gene coding regions $(\mathrm{n}=59)$ of pRS218 in other NMEC and fecal E. coli strains. Primers were designed using the Primer 3.0 web tool (http://bioinfo.ut.ee/primer3-0.4.0/) (Table 5). PCR amplifications were performed using crude DNA extracted by the rapid boiling method [38]. The PCR mixture contained $1 \mathrm{U}$ of Taq polymerase (Qiagen), 1× Taq polymerase buffer, 3.5 $\mathrm{mM} \mathrm{MgCl}_{2}, 125 \mu \mathrm{M}$ each deoxynucleotide triphosphate (dNTP) and150 nM each primer pair. PCR conditions were as follows: 1 cycle of $95^{\circ} \mathrm{C}$ for $1 \mathrm{~min}$, followed by 30 cycles of $95^{\circ} \mathrm{C}$ for $30 \mathrm{~s}, 55^{\circ} \mathrm{C}$ for $30 \mathrm{~s}$, and $72^{\circ} \mathrm{C}$ for $1.5 \mathrm{~min}$, and a final extension at $72^{\circ} \mathrm{C}$ for $10 \mathrm{~min}$. Amplicons were visualized on a $1.5 \%$ agarose gel containing $0.5 \mu \mathrm{g} / \mathrm{ml}$ ethidium bromide.

\section{Plasmid curing and complementation}

The plasmid stability gene, $s t b A$ of pRS218 was mutated by using a phage lambda Red recombinase system to facilitate plasmid curing [39]. Briefly, the chloramphenicol resistance cassette (cat) was amplified with PCR by using pKD3 plasmid as the template and primers consisted of 36 nucleotides extensions at $5^{\prime}$ and $3^{\prime}$ ends of $s t b A$ (forward primer 5' - ATG AAC GTA TAC TGC GAT GAT GGT TCA ACA ACA ATC GTG TAG GCT GGA GCT GCT TC-3' and reverse primer 5' -TAC TCC TCT TTG AAA GCC GCG ATA GCT TCA ACC AGT CAT ATG AAT ATC CTC CTT AG-3'). Amplified product was gel purified (MiniElute Kit, Qiagen) and electroporated to E. coli RS218 carrying the Red helper plasmid, pKD119. Mutants (RS218:pRS218 $\Delta s t b A:: c a t)$ were selected for chloramphenicol resistance and confirmed by PCR using primers specific to $s t b A$. Plasmid curing was done as described previously by $10 \%$ sodium dodecyl sulfate treatment [40]. Plasmid curing was confirmed by comparing the plasmid profile of the cured strain with the parent strain. The isolate which did not possess the plasmid was further verified for curing by PCR amplification of 5 genes or ORFs, $\operatorname{sen} B$ (forward primer 5' - GCA GAT TCG CGT TTT GAG CA-3' and reverse primer 5' - CGG ATC TTT CAA CGG GAT GG-3'), scsD (forward primer 5' - CAT ACG CTG GAC GGG GAA AC-3' and reverse primer 5'-GAC GCT CTC CCC TTC CGA CT-3'), traU (forward primer 5' - TTC CTT CTC GCC GGT CAT GT-3' and reverse primer 5' - CCA GCG AGA GCG GGA AAA TA-3'), transposase (forward primer 5'- GCT TCG GGA ACG CTG TAA CG-3' and reverse primer 5' - AGA AGG CTG CGG TGC TGA AG-3'), pRS218_113 (forward primer 5' - TGG GGG CTG AAA ACC AGA GA-3' and reverse primer $5^{\prime}$ - ACC GAA GGC ACG AAC TGC AT-3'), and $y c f A$ (forward primer 5'- CGC CTG GTG GTG AAG GAA AG-3' and reverse primer 5'- GAC CAC CTC CCG CAG AAC AC-3') of pRS218. Isolates that did not possess all of the five genes/ORFs were considered to be cured of pRS218.

The plasmid complementation was performed using conjugation as described previously [41]. The main obstacle for complementation was the absence of an antibiotic resistance marker in pRS218 which could have been used for subsequent selection. Therefore, pRS218 was first tagged with cat using the one step inactivation method [39]. Briefly, the cat was amplified using pKD3 plasmid and primers consisted of 36 nucleotides extensions at $5^{\prime}$ and $3^{\prime}$ ends of a putative noncoding region of pRS218 located between base pairs 591 and 831 in the plasmid sequence (Forward primer 5'-CGC CTT CGC GTT GCT CAG TTG TCC AAC CCC GGA AAC GTG TAG GCT GGA GCT GCT TC-3' and reverse primer 5' -CTC CTC AAT ACT CAA ACA GGG ATC GTT TCG CAG AGG ACA TAT GAA TAT CCT CCT TAG-3'). Purified PCR 
Table 5 Primers used for the screening of pRS218 genes among neonatal meningitis causing $E$. coli and fecal commensal $E$. coli strains

\begin{tabular}{|c|c|c|c|c|c|}
\hline $\begin{array}{l}\text { Coordinates } \\
\text { in pRS218 }\end{array}$ & Gene name & Predicted function & Primer F $\left(5^{\prime}-3^{\prime}\right)$ & Primer R (5'-3') & $\begin{array}{l}\text { Product } \\
\text { size (bp) }\end{array}$ \\
\hline $4107-4265$ & pRS218_007 & Copper sensitivity & gagacgttgagcaccaatctg & accgccagtttttctttcac & 140 \\
\hline $4255-4761$ & pRS218_008 & Copper sensitivity & catacgctggacggggaaac & gacgctctccccttccgact & 143 \\
\hline 4998- 5759 & pRS218_010 & $\mathrm{Na}+$ traslocation & atcaatgatggtgctttgtgtc & ccggtaactggaatgataacct & 378 \\
\hline $6052-7992$ & pRS218_013 & Iron permease & gtgttcgagaacctggaagg & cggttttgtctgagggacat & 401 \\
\hline 8033- 8560 & pRS218_014 & Iron transport & ctgtcaccatgaatgaaatgga & ctcacatcaaacggtttccac & 400 \\
\hline 8664- 10043 & pRS218_015 & Membrane protein & tcgtgacggtaaactgcatc & gccgccatagctgtatttgt & 400 \\
\hline 10046- 11329 & pRS218_016 & $\mathrm{ABC}$ transporter & aaggggtggtgatcgataaaat & catacagcacctccacaggata & 399 \\
\hline 11319- 12449 & pRS218_017 & Membrane protein & aggtcaccggtagctggatt & atcgagaccagtcccatcag & 400 \\
\hline 12454- 13149 & pRS218_018 & $\mathrm{ABC}$ transporter & gttccatttgatcccgttctta & acccagatatttaccgtgttgc & 379 \\
\hline 13136- 13621 & pRS218_019 & Putative thioredoxin precursor & gcgggtgtaaagaagaaaagc & agacggcttacgcataccc & 401 \\
\hline 13646- 14131 & pRS218_020 & Hypothetical protein & atagcgcaactgcttcacacta & acgttccgtatcgacaaattct & 303 \\
\hline 14253- 14702 & pRS218_022 & Glucose-1-phosphatase & agacaacgccggaaggttat & tttcctgatgatgtaccggaat & 354 \\
\hline 14677- 14997 & pRS218_023 & Glucose-1-phosphatase & acgatggacccaacgtttaat & ataggctgattcgatgtgtttg & 311 \\
\hline 18173- 17826 & pRS218_031 & Hypothetical protein & attgecctgatggacagc & gtggcagccggttaacttt & 301 \\
\hline $20251-20775$ & pRS218_034 & Colicin immunity & ttaataatatgtggtggggatgg & atgaaaacagtacccgtataaacagc & 250 \\
\hline $21065-21982$ & pRS218_035 & ColicinJ production & tggcttattcaaaatttgctcat & tgcatagatatgatggtttcacg & 350 \\
\hline $21990-22766$ & pRS218_036 & ColicinJ production & ctgattttccttgcgtttatctg & agcctttatcttacgaggtggac & 294 \\
\hline $22935-25196$ & pRS218_038 & ColicinJ production & tatgatgcaggttttgcttttg & tggcatcatgttgagcttattc & 393 \\
\hline $25265-26440$ & pRS218_039 & Enterotoxin & gcagattcgcgttttgagca & cggatctttcaacgggatgg & 302 \\
\hline 28517- 27762 & pRS218_042 & Hypothetical protein & tgacgctatgcaatgaagaact & tgacatagccaagatcatccac & 399 \\
\hline $38291-37500$ & pRS218_056 & Hypothetical protein & cgtccacggattatgtctataaaac & gtatgacgggatgatttcagataac & 373 \\
\hline 40184- 38298 & pRS218_057 & ColicinJ production & ctgtggataacagcctcatcaa & atgttaaccgggtagcttttca & 301 \\
\hline 43799-42630 & pRS218_060 & Hypothetical protein & ctcttccccatggectttat & accccatactgcattggaaa & 600 \\
\hline $46748-46975$ & pRS218_063 & Hypothetical protein & tggatcctttgttgatcattcat & cctgtaaagacagacttcagaaaaa & 224 \\
\hline $48251-47610$ & pRS218_064 & Hypothetical protein & tcgacctaacccttgatcagtt & tatagcgacaggatggacagtg & 385 \\
\hline $52321-52046$ & pRS218_073 & Hypothetical protein & cagccagcaagcattaaaca & gctcaagggctactctgacg & 276 \\
\hline 53188- 54159 & pRS218_074 & Stability protein StbA & ttgtcgcaaaactcatttcg & cgaccagacgagaaaacaca & 400 \\
\hline 56513- 56265 & pRS218_079 & Hypothetical protein & cgcattgaaattcttttcgac & tcgtcctgccagatttcttc & 249 \\
\hline 56648- 57166 & pRS218_080 & Unknown & gtgttcgtgatctcgtttcgta & ttgcccactttcttaatcttcc & 351 \\
\hline 58824- 59654 & pRS218_082 & Hypothetical protein & acaaatgaaggtattcagctgtttc & cgacagtacgttgtcacacagac & 372 \\
\hline $60445-59648$ & pRS218_083 & Transposase & gcttcgggaacgctgtaacg & agaaggctgcggtgctgaag & 414 \\
\hline 61858- 62169 & pRS218_086 & Hypothetical protein & ttttccggtaaaggatgtcg & gtctttctgacggcaaggctat & 223 \\
\hline $62245-62928$ & pRS218_088 & Adenine-specific methyltransferase & cggtgatgttaatgatgactgg & gtgtgaagctctcaatcagtgg & 356 \\
\hline $62929-63150$ & pRS218_089 & Cytoplasmic protein & ctatgccggacacgaaaaac & gaagcaggaatccagttcca & 208 \\
\hline 63230- 63598 & pRS218_090 & Hypothetical protein & gttatctggtccccggaaga & cattcacgtttccacaatgc & 254 \\
\hline 63643- 64614 & pRS218_091 & Hypothetical protein & atgaatgaaatgctgaatgcac & catcttctgccacctggtaact & 406 \\
\hline $63643-64614$ & pRS218_091 & Hypothetical protein & cgcctggtggtgaaggaaag & gaccacctcccgcagaacac & 236 \\
\hline 64828- 65253 & pRS218_092 & Putative antirestriction protein & gttgaagagtgcgaccgtct & agtcaagtgccgcgtaaatc & 400 \\
\hline 65300- 65722 & pRS218_093 & Phage protein MubC & catccgcgatgtactggatac & ctgtaacacaacgtccattgct & 373 \\
\hline 65719- 65910 & pRS218_094 & Hypothetical protein & cacagaaacccgcgaaat & ctgtttctgctgccctgtaag & 177 \\
\hline $66381-65887$ & pRS218_095 & Hypothetical protein & cttacatcccggcgtcgt & cctgatgttatgtttctgtggttact & 256 \\
\hline $67155-68516$ & pRS218_099 & Hypothetical protein & tatggcaaaactcatcagcagt & gtaatttggcgttgtgactgaa & 385 \\
\hline 68563-69126 & pRS218_100 & Hypothetical protein & tctcagctttttgtgagtcctg & aaaacggtaacagcttctcctg & 400 \\
\hline 70556- 70789 & pRS218_105 & Cytoplasmic protein & gcgaatatttcagaatacttcagg & aattccggatgacatggttc & 213 \\
\hline 70848- 72806 & pRS218_106 & Hypothetical protein & agtgtgaggaatctgacctgct & taatgtttacattccaggctgattt & 400 \\
\hline
\end{tabular}


Table 5 Primers used for the screening of pRS218 genes among neonatal meningitis causing $E$. coli and fecal commensal $E$. coli strains (Continued)

\begin{tabular}{|c|c|c|c|c|c|}
\hline $72861-73271$ & pRS218_107 & Adenine-specific methyltransferase & ataccatgaacgcacaggaata & ggatgatgtcgttaacgctgta & 371 \\
\hline 74286- 74444 & pRS218_109 & Hok/Gef cell toxic protein & atgaaactaccacgcagctctc & taccggattcgtaagccatga & 154 \\
\hline 75004- 74681 & pRS218_110 & Hypothetical protein & gcgttgcgccttacatcc & tcacatcaccttccctttgatt & 314 \\
\hline $75360-75647$ & pRS218_113 & Hypothetical protein & gagtacccgaaatatccacgtt & taatctgacgcaggaactgttt & 251 \\
\hline $75360-75647$ & pRS218_113 & Hypothetical protein & tgggggctgaaaaccagaga & accgaaggcacgaactgcat & 531 \\
\hline $75691-76587$ & pRS218_114 & Unknown & tcggtattttccggtgataaac & ataacctgcccgacaatatcac & 359 \\
\hline 77473- 76883 & pRS218_116 & X polypeptide & aggccgggattacaaaatagat & ccggtataaatccggtaaacct & 354 \\
\hline 7839479080 & pRS218_118 & TraJ/conjugal transfer & caatggggcttttattgaactc & tgaccaacacccagcatataaa & 369 \\
\hline 85396- 85614 & pRS218_131 & Hypothetical protein & tgcatacctttatttttcttgtgc & tcagtgtatccatcacgttgttc & 210 \\
\hline 89620-90612 & pRS218_136 & TraU/conjugal transfer & ttccttctcgccggtcatgt & ccagcgagagcgggaaaata & 111 \\
\hline 105274- 110544 & pRS218_154 & Tral/conjugal transfer & gcgatgcggtcagtgttctg & ggacagccgttcatcctgct & 190 \\
\hline 111369- 112229 & pRS218_156 & Dienelactone hydrolase & tctggttaccggagagatgaat & agtaccagaagcaacagcatca & 343 \\
\hline $113415-113939$ & pRS218_159 & Hypothetical protein & gtgccatttatctgatatggagaat & tctgtgttgtactgctcatataccc & 387 \\
\hline $113985-114194$ & pRS218_190 & Hemolysin expression modulating protein & caaaacaggaatggctgtatca & tatttccatatctcttttggtatcctg & 190 \\
\hline
\end{tabular}

product was electroporated to E. coli RS218 carrying the Red helper plasmid pKD119 to construct the pRS218::cat. The temperature sensitive pKD119 plasmid was removed from pRS218::cat by growing at $42^{\circ} \mathrm{C}$ followed by screening for tetracycline sensitivity. The E. coli RS218 carrying pRS218::cat was then used as the donor to perform mating experiments. Escherichia coli DH5 $\alpha$ was used as an intermediate recipient to transfer pRS218::cat from the donor strain to the recipient plasmid-cured strain.

\section{Bacterial growth curve}

Bacteria were grown in LB broth at $37^{\circ} \mathrm{C}$ with shaking overnight. Cultures were diluted to 1:100 with LB broth, tissue culture medium or M9 medium with $10 \mu \mathrm{g} / \mathrm{ml}$ niacin and incubated at $37^{\circ} \mathrm{C}$ with shaking. Optical density at $600 \mathrm{~nm}$ (OD600) was taken in triplicate for every 20 min for 6 hrs. The OD values from each time point were averaged and graphed to obtain a growth curve.

\section{In vitro invasion assay}

Invasion assays were performed using hCMEC/D3 cells provided by Dr. Weksler B, Cornell University, NY. The hCMEC/D3 cells were grown in endothelial basal medium (Lonza, Walkersville, MD) containing 5\% fetal bovine serum (PAA The Cell Culture Company, Piscataway, NJ), 1.4 $\mu \mathrm{M}$ hydrocortisone (Sigma-Aldrich, St. Louis, MO.), 5 $\mu \mathrm{g} \cdot \mathrm{ml}^{-1}$ acid ascorbic (Sigma), 1\% chemically defined lipid concentrate (Gibco, Carlsbad, CA), 10 mM HEPES (PAA The Cell Culture Company), and 1 ng. $\mathrm{ml}^{-1}$ human basic fibroblast growth factor (Sigma), The invasion assay was performed as described previously [32]. Briefly, endothelial cells were seeded at about $1 \times 10^{5}$ cells per well in 12-well tissue culture plates (Corning Life Sciences, Manassas, VA.) coated with rat collagen (R\&D Systems, Trevigen, Gaithersburg, MD) and incubated at $37^{\circ} \mathrm{C}$ with $5 \% \mathrm{CO}_{2}$ in a humid chamber. Once the monolayer was confluent, it was washed with phosphate-buffered saline (PBS, pH 7) and incubated with the cell culture medium containing bacteria at a multiplicity of infection (MOI) of 100 for 2 hrs at $37^{\circ} \mathrm{C}$ with $5 \% \mathrm{CO}_{2}$ to allow cellular invasion [32]. The extracellular bacteria were eliminated by incubation of the monolayers with a culture medium containing gentamicin $(100 \mu \mathrm{g} / \mathrm{ml})$ for $1 \mathrm{~h}$. The monolayers were washed three times with PBS and lysed with $0.1 \%$ Triton X-100. The intracellular bacteria that were released during cell lysis were enumerated by plating on LB agar plates. Invasion frequencies were calculated by dividing the number of invaded bacteria by the initial inoculum and expressed as a percentage relative to the invasion frequency of wtRS218. The assays were performed three times in triplicate and student's $t$ test was used to compare the groups.

\section{Neonatal rat meningitis model}

Five-day-old Sprague-Dawley out-bred rat pups $(\mathrm{n}=10)$ were used in each experimental group. Rat pups were injected with approximately 200 CFU (range160 to 210 CFU) of E. coli (wtRS218 and RS218 cured $_{\text {) by the intra- }}$ peritoneal route. For the negative control group, PBS was injected intraperitoneally. Mortalities of rat pups in each group were monitored for $24 \mathrm{hrs}$ post-inoculation. The pups that survived were euthanized 24 hrs postinoculation to collect blood, cerebrospinal fluid (CSF) and brain tissues. For bacterial enumeration, blood was collected by intra-cardiac puncture and plated on MacConkey agar to detect septicemia. Cerebrospinal fluid was collected by cisternal puncture, and plated on MacConkey agar to demonstrate meningitis. Brain tissues collected from each group were fixed in $10 \%$ neutral-buffered formalin, routinely processed for histopathology, stained with haematoxylin-eosin, and examined 
for lesions consistent with bacterial meningitis. Experiments were done in triplicates and the paired $t$ test was used to compare the experimental groups.

\section{Ethics statement}

Protocols involving rat experiments complied with federal guidelines and the policies of the Institutional Animal Care and Use Committee (IACUC) of the Pennsylvania State University (University Park, PA). Both NMEC and HFEC isolates, in their entirety, were collected for purposes other than this study and were given without any Health Insurance Portability and Accountability Act (HIPAA) identifiers by Dr. K.S. Kim (John Hopkins University, Baltimore, MD).

\section{Competing interests}

The authors declare that no competing interests exist.

\section{Authors' contributions}

DSSW conceived the study, performed most of the laboratory work, interpreted the results and drafted the manuscript. KHEMK participated in in vitro invasion assays and animal experiments. AC helped in plasmid gene screen and animal experiments. RK and VK assisted in plasmid sequencing and annotation. EGD assisted in plasmid complementation and revised the manuscript. CD provided some E. coli strains, performed serotyping and revised the manuscript. SK designed and coordinated the study, and helped in data interpretation and preparation of the manuscript. All authors read and approved the final manuscript.

\section{Acknowledgements}

The authors thank Dr. K.S. Kim (Johns Hopkins University, Baltimore, MD) for providing meningitic bacterial isolates used in this study. We also acknowledge Dr. P.O. Couraud (Institut Cochin, Université Paris Descartes, CNRS (UMR 8104), Paris, France), Dr. I.A. Romero (The Open University, Milton Keynes, UK) and Dr. B. Weksler (Weill Cornell Medical College, New York, USA) for providing hCMEC/D3 for this study.

\section{Author details}

'Department of Veterinary and Biomedical Sciences, Pennsylvania State University, 16802 University Park, PA, USA. ${ }^{2}$ Department of Food Science, Pennsylvania State University, 16802 University Park, PA, USA. ${ }^{3}$ Center for Molecular Immunology and Infectious Disease, 16802 University Park, PA, USA.

Received: 17 March 2014 Accepted: 18 July 2014

Published: 28 August 2014

\section{References}

1. Lawn JE, Cousens S, Zupan J: 4 million neonatal deaths: when? Where? Why? Lancet 2005, 365(9462):891-900.

2. Liu L, Johnson HL, Cousens S, Perin J, Scott S, Lawn JE, Rudan I, Campbell H, Cibulskis R, Li M, Mathers C, Black R: Global, regional, and national causes of child mortality: an updated systematic analysis for $\mathbf{2 0 1 0}$ with time trends since 2000. Lancet 2012, 379(9832):2151-2161.

3. Bell AH, Brown D, Halliday HL, McClure G, McReid M: Meningitis in the newborn-a 14 year review. Arch Dis Child 1989, 64(6):873-874

4. Kim KS: Strategy of Escherichia coli for crossing the blood-brain barrier. $J$ Infect Dis 2002, 186(Supplement 2):S220-S224.

5. Kim KS: Pathogenesis of bacterial meningitis: from bacteraemia to neuronal injury. Nat Rev Neurosci 2003, 4(5):376-385.

6. Frosch M, Edwards U, Bousset K, Krauße B, Weisgerber C: Evidence for a common molecular origin of the capsule gene loci in Gram-negative bacteria expressing group II capsular polysaccharides. Mol Microbiol 1991, 5(5):1251-1263.

7. Pong A, Bradley JS: Bacterial meningitis and the newborn infant. Infect Dis Clin North Am 1999, 13(3):711-733.
8. Polin RA, Harris MC: Neonatal bacterial meningitis. Sem Neonatol 2001, 6(2):157-172.

9. Jain R, Rivera MC, Moore JE, Lake JA: Horizontal gene transfer accelerates genome innovation and evolution. Mol Biolo Evol 2003, 20(10):1598-1602.

10. Johnson TJ, Nolan LK: Pathogenomics of the virulence plasmids of Escherichia coli. Microbiol Mol Biol Rev 2009, 73(4):750-774.

11. Carattoli A: Plasmids and the spread of resistance. Int/ J Med Microbiol 2013, 303(6-7):298-304.

12. Cusumano CK, Hung CS, Chen SL, Hultgren SJ: Virulence plasmid harbored by uropathogenic Escherichia coli functions in acute stages of pathogenesis. Infect Immun 2010, 78(4):1457-1467.

13. DebRoy C, Sidhu MS, Sarker U, Jayarao BM, Stell AL, Bell NP, Johnson TJ: Complete sequence of pEC14_114, a highly conserved IncFIB/FIIA plasmid associated with uropathogenic Escherichia coli cystitis strains. Plasmid 2010, 63(1):53-60.

14. Peigne $C$, Bidet $P$, Mahjoub-Messai F, Plainvert C, Barbe V, Médigue C, Frapy E, Nassif X, Denamur E, Bingen E, Bonacorsi S: The plasmid of Escherichia coli Strain $\mathrm{S} 88(\mathrm{O} 45: \mathrm{K} 1 \mathrm{H}$ ) that causes neonatal meningitis is closely related to avian pathogenic $E$. coli plasmids and is associated with high-level bacteremia in a neonatal rat meningitis model. Infect Immun 2009, 77(6):2272-2284.

15. Lu S, Zhang X, Zhu Y, Kim KS, Yang J, Jin Q: Complete genome sequence of the neonatal-meningitis-associated Escherichia coli strain CE10. J Bacteriol 2011, 193(24):7005.

16. Silver RP, Aaronson W, Vann WF: The K1 capsular polysaccharide of Escherichia coli. Rev Infect Dis 1988, 10(2):S282-S286.

17. Silver RP, Aaronson W, Sutton A, Schneerson R: Comparative analysis of plasmids and some metabolic characteristics of Escherichia coli K1 from diseased and healthy individuals. Infect Immun 1980, 29(1):200-206.

18. Tivendale KA, Logue CM, Kariyawasam S, Jordan D, Hussein A, Li G, Wannemuehler Y, Nolan LK: Avian-pathogenic Escherichia coli strains are similar to neonatal meningitis $E$. coli strains and are able to cause meningitis in the rat model of human disease. Infect Immun 2010, 78(8):3412-3419.

19. Verkhovsky MI, Bogachev AV, Pivtsov AV, Bertsova YV, Fedin MV, Bloch DA, Kulik LV: Sodium-dependent movement of covalently bound FMN Residue(s) in Na+-Translocating NADH: quinone oxidoreductase. Biochemistry 2012, 51(27):5414-5421.

20. Lehoux IE, Mazzulla MJ, Baker A, Petit CM: Purification and characterization of YihA, an essential GTP-binding protein from Escherichia coli. Protein Expr Purif 2003, 30(2):203-209.

21. Ripio MT, Brehm K, Lara M, Suárez M, Vázquez-Boland JA: Glucose-1-phosphate utilization by Listeria monocytogenes is PrfA dependent and coordinately expressed with virulence factors. J Bacteriol 1997, 179(22):7174-7180.

22. Scheurwater E, Reid CW, Clarke AJ: Lytic transglycosylases: bacterial space-making autolysins. Int I Biochem Cell Biol 2008, 40(4):586-591.

23. Toh H, Oshima K, Toyoda A, Ogura Y, Ooka T, Sasamoto H, Park S-H, lyoda S, Kurokawa K, Morita H, Itoh K, Taylor TD, Hayashi T, Hattori M: Complete genome sequence of the wild-type commensal Escherichia coli strain SE15, belonging to phylogenetic group B2. J Bacteriol 2010, 192(4):1165-1166.

24. Wajima T, Sabui S, Kano S, Ramamurthy T, Chatterjee NS, Hamabata T: Entire sequence of the colonization factor coli surface antigen 6-encoding plasmid pCss165 from an enterotoxigenic Escherichia coli clinical isolate. Plasmid 2013, 70(3):345-352.

25. Zhang W, Bielaszewska M, Kunsmann L, Mellmann A, Bauwens A, Köck R Kossow A, Anders A, Gatermann S, Karch H: Lability of the pAA virulence plasmid in Escherichia coli O104:H4: implications for virulence in humans. PLoS One 2013, 8(6):e66717.

26. Logue CM, Doetkott C, Mangiamele P, Wannemuehler YM, Johnson TJ, Tivendale KA, Li G, Sherwood JS, Nolan LK: Genotypic and phenotypic traits that distinguish neonatal meningitis-associated Escherichia coli from fecal E. coli isolates of healthy human hosts. Appl Environ Microbiol 2012, 78(16):5824-5830.

27. Nakaya R, Nakamura A, Murata Y: Resistance transfer agents in Shigella. Biochem Biophys Res Commun 1960, 3:654-659.

28. Grass G, Rensing C, Solioz M: Metallic copper as an antimicrobial surface. Appl Environ Microbiol 2011, 77(5):1541-1547.

29. Gupta SD, Wu HC, Rick PD: A Salmonella typhimurium genetic locus which confers copper tolerance on copper-sensitive mutants of Escherichia coli. J Bacteriol 1997, 179(16):4977-4984. 
30. Nataro JP, Seriwatana J, Fasano A, Maneval DR, Guers LD, Noriega F, Dubovsky F, Levine MM, Morris JG: Identification and cloning of a novel plasmid-encoded enterotoxin of enteroinvasive Escherichia coli and Shigella strains. Infect Immun 1995, 63(12):4721-4728.

31. Badger JL, Wass CA, Weissman SJ, Kim KS: Application of signature-tagged mutagenesis for identification of Escherichia coli K1 genes that contribute to invasion of human brain microvascular endothelial cells. Infect Immun 2000, 68(9):5056-5061.

32. Huang SH, Wass C, Fu Q, Prasadarao NV, Stins M, Kim KS: Escherichia coli invasion of brain microvascular endothelial cells in vitro and in vivo: molecular cloning and characterization of invasion gene ibe10. Infec Immun 1995, 63(11):4470-4475.

33. Sambrook J, Russell DW: Molecular cloning: a laboratory manual. In, Volume 1. 4th edition. New York: Cold Spring Harbor Laboratory Press; 2012.

34. Aziz R, Bartels D, Best A, DeJongh M, Disz T, Edwards R, Formsma K, Gerdes S, Glass E, Kubal M, Meyer F, Olsen G, Olson R, Osterman A, Overbeek R, McNeil L, Paarmann D, Paczian T, Parrello B, Pusch G, Reich C, Stevens R, Vassieva O, Vonstein V, Wilke A, Zagnitko O: The RAST server: rapid annotations using subsystems technology. BMC Genomics 2008, 9(1):75.

35. Darling ACE, Mau B, Blattner FR, Perna NT: Mauve: multiple alignment of conserved genomic sequence with rearrangements. Genome Res 2004, 14(7):1394-1403.

36. Hall BG: Building phylogenetic trees from molecular data with MEGA. Mol Biol Evol 2013, 30(5):1229-1235.

37. Saitou N, Nei M: The neighbor-joining method: a new method for reconstructing phylogenetic trees. Mol Biol Evol 1987, 4(4):406-425.

38. Johnson JR, Stell AL: Extended virulence genotypes of Escherichia coli strains from patients with urosepsis in relation to phylogeny and host compromise. J Infect Dis 2000, 181(1):261-272.

39. Datsenko KA, Wanner BL: One-step inactivation of chromosomal genes in Escherichia coli K-12 using PCR products. Proc Natl Acad Sci 2000 97(12):6640-6645.

40. El-Mansi M, Anderson KJ, Inche CA, Knowles LK, Platt DJ: Isolation and curing of the Klebsiella pneumoniae large indigenous plasmid using sodium dodecyl sulphate. Res Microbiol 2000, 151(3):201-208.

41. Dudley EG, Abe C, Ghigo J-M, Latour-Lambert P, Hormazabal JC, Nataro JP: An Incl1 plasmid contributes to the adherence of the atypical enteroaggregative Escherichia coli Strain C1096 to cultured cells and abiotic surfaces. Infect Immun 2006, 74(4):2102-2114.

doi:10.1186/s12866-014-0203-9

Cite this article as: Wijetunge et al:: Complete nucleotide sequence of pRS218, a large virulence plasmid, that augments pathogenic potential of meningitis-associated Escherichia coli strain RS218. BMC Microbiology 2014 14:203.

\section{Submit your next manuscript to BioMed Central and take full advantage of:}

- Convenient online submission

- Thorough peer review

- No space constraints or color figure charges

- Immediate publication on acceptance

- Inclusion in PubMed, CAS, Scopus and Google Scholar

- Research which is freely available for redistribution 